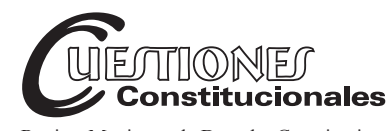

Revista Mexicana de Derecho Constitucional Núm. 43, julio-diciembre 2020

\title{
La democracia participativa, respuesta a la crisis de la democracia representativa
}

\author{
Participatory democracy, a response to the crisis \\ of representative democracry
}

\section{Emilio RABASA GAMBOA*}

RESUMEN: La tesis central del artículo consiste en argumentar que la crisis de la democracia representativa, debido a una fatiga política que ha generado el descontento y la desconfianza de los ciudadanos representados, con sus representantes, ha provocado el surgimiento, sobre todo en este siglo, de diversos mecanismos de democracia directa, como la consulta popular, el referéndum, el plebiscito, la revocación del mandato y otras que se analizan en el texto.

Para fundamentar teóricamente la tesis, se incluyen varios autores de actualidad que han abordado el tema de la crisis de la democracia y las elecciones, como Levitsky y Ziblatt (Cómo mueren las democracias), Yasch Mounk (El pueblo vs la democracia), Temelkuran (Cómo perder un país), Cadena Roa y López Leyva (El malestar con la representación en México) y Van Reybrouck (Contra las elecciones - cómo salvar la democracia). De igual manera, se analiza a mayor profundidad el origen de esa crisis en la génesis de la democracia representa-
ABSTRACT: The central thesis of this article consists in argueing that the actual crisis of representative democracy, due to a political fatigue that has caused a descontent and mistrust of the represented citicenship by their representatives, has provoked mainly in this century, the emergence of diverse mechanisms of direct democracy such as popular consultation, referendum, plebiscite, mandate recall and others analized in the text.

To provide theoretical foundation to my thesis, several updated authors that have researched the crisis of democracy and elections, are included such as Levitsky y Ziblatt (How Democracies Die), Yasch Mounk (The People vs Democracy), Temelkuran (How to lose a country), Cadena Roa y López Leyva (The disconfort with representation in Mexico) y Van Reybrouck (Against elections, how to save democracy). In the same token and at more depth, the present crisis is analyzed through the genesis and design of representative democracy with autors such

* Licenciado y doctorado en derecho por la UNAM; maestría en Cambridge University, Inglaterra, en Filosofía y Ciencia Política. Actualmente es investigador del Instituto de Investigaciones Jurídicas y docente en la UNAM. ORCID: 0000-0003-2845-1420. México. Correo electrónico: erabasa@unam.mx. 
tiva y su diseño, con autores como Benjamin Constant, Hans Kelsen y Roberto Gargarella, a fin de argumentar que esta crisis tiene su origen desde el siglo XVIII, pero ahora se ha acentuado por el cambio de las condiciones económicas, como la caída del creciente bienestar de los treinta a los ochenta del siglo pasado; sociales, como la creciente migración y nueva composición pluriétnica de las sociedades modernas, y la revolución de las comunicaciones con el Internet y las redes sociales.

En seguida, se analizan los distintos tipos de democracia (representativa, directa, deliberativa y radical), a fin de proponer la fusión armónica de diversos componentes de la democracia representativa con otros de la democracia participativa) como una solución a la crisis política actual. Se incluye un análisis comparativo de otros países latinoamericanos que lo han intentado, como Venezuela, Ecuador y Bolivia, y se presentan los mecanismos de democracia directa vigentes en México tanto en la Constitución federal (incluida la reforma de diciembre del 2019) como en la Constitución de la Ciudad de México y de otras entidades federativas, como sustento a la tesis central del artículo.

Se concluye contraargumentando sobre las dificultades de una ingeniería constitucional que fusionara los dos tipos de democracia.

Palabras clave: democracia representativa, fatiga democrática, democracia participativa, crisis de la democracia actual, modalidades de democracia directa en México (consulta popular, referéndum, plebiscito, revocación de mandato), la fusión democrática. as Benajmin Contant, Hans Kelsen and Roberto Gargarella, in order to argue that its origin lies in the XVIII Century, but has now become more acute due to changing economic condictios in societies fallen wellbeing that grew during last century's 30 s and 80s; social such as the growth of migration and the new pluriethnic changes in modern societies composition, and the comunicaions revolution with internet and social media.

Next is included an analysis of democracy's types (representative, direct, paritipatory, deliberative and radical) with the purpose of proposing an armonic fusion of representative democracy's diverse components with others of participatory democracy, as a solution to the present political crisis. Other countries'experience in that road in Latin America such as Ecuador, Venezuela and Bolivia are included to grasp a comparative view. Finally Mexico's direct democracy's mechanisms in force in the federal constitution (including the recent constitucional reform of December 2019) Mexico's City constitution and other states, are presented to support the main thesis of this article.

Closing remarks include counter-argument about the difficuties of constitutional engeniering for melting together both types of democracy.

Keywords: representative democracy, democratic fatigue, participatory democracy, democracy's present day crisis, Mexico's direct democracy types (popular consultation, referendum, plebiscite, mandate recall) democratic melting. 
Hoy en día las democracias occidentales se enfrentan tanto a una crisis de legitimidad como de eficiencia. Es algo excepcional: la situación ha dejado de ser una simple marejada para convertirse en el preludio de una tempestad

David VAN REYBROUCK

\begin{abstract}
SUMARIO: I. Introducción: la crisis de la democracia representativa. II. Las críticas a la democracia representativa. III. Tipología de la democracia. IV. Modalidades de democracia directa en México. V. Conclusiones. VI. Bibliografía.
\end{abstract}

\title{
I. INTRODUCCIÓN: LA CRISIS DE LA DEMOCRACIA REPRESENTATIVA
}

El desencanto que ha venido provocando desde la alborada del siglo presente la democracia representativa, la forma de gobierno más extendida ${ }^{1}$ en el planeta, debido a un agotamiento prematuro, ${ }^{2}$ que con gran acierto el filósofo belga David van Reybrouck ha caracteriza como "el síndrome de fatiga democrática", ${ }^{3}$ ha ocasionado el surgimiento de diversos tipos de respuestas políticas al desinterés ciudadano cada día más generalizado por esa gobernanza. El incremento en el abstencionismo electoral, combinado con una mayor fluctuación partidista y la sensible disminución en la afiliación ciudadana en los partidos políticos, ha generado una crisis de legitimidad y eficiencia en la democracia representativa. ${ }^{4}$

1 Según el reporte de Freedom House, Freedom in the World, 2013, Democratic Breakthroughs in the Balance, Londres 2013, pp. 28 y 29, en 1972 había 44 Estados libres, y 73 en 1993. Hoy ya son 117 de 195. Citado por Van Reybuck, David, 2017, p. 12. El autor (Brujas, 1971) es doctor por la Universidad de Leiden. En 2011 lanzó el G1000, una cumbre ciudadana y organización que funciona como plataforma para la innovación democrática en Bélgica.

2 Prematuro, porque la tercera ola de democratización (Samuel Huntinghton) apenas tiene aproximadamente treinta años de haberse iniciado. Véase mi libro Rabasa Gamboa, Emilio, 1993, en donde se explica la transición de más de treinta países de diferente grado de desarrollo económico y social de diversas formas de autoritarismo a la democracia representativa.

3 Van Reybruck, David, op. cit., 2017, pp. 49 y 51.

4 Sintomatología de la crisis de la democracia representativa según David van Reybuck, en ibidem, pp.17-27. 
La crisis de la fatiga democrática no es privativa de un país o de un grupo de países de características comunes, pues se ha extendido a los cuatro continentes, y abarca a naciones de diferentes antecedentes y contextos históricos y culturales. El "desmoronamiento de la aceptación pública" (deslegitimidad) y el "deterioro de la capacidad de resolución" (ineficiencia) ${ }^{5}$ son globales, y su causa última, según el autor citado, es que "nos hemos convertido en fundamentalistas electorales. Despreciamos a los elegidos pero idolatramos a las elecciones". ${ }^{6}$

Deseo argumentar como hipótesis básica de este artículo, que la crisis del agotamiento de la democracia representativa, cada vez más evidente en el siglo presente, ha generado como reacción o respuesta una reactivación política de los representados, que cada día desconfían más de sus representantes, a través de mecanismos de democracia directa; esto es, vivimos un momento de reconvención política. No se trata de una simple tensión entre ambas formas de democracia, sino de toda una reingeniería constitucional de la primera con la segunda.

El problema del desencanto con la democracia representativa se inserta en un marco de debate de mayor amplitud y profundidad, que se refiere a la subsistencia misma de la democracia. Al filo de la primera década de este siglo ha surgido una amplia literatura sobre la amenaza y el ocaso democrático ligado al surgimiento del populismo en no pocos países. Es importante vislumbrar ese horizonte, que permitirá entender mejor la hipótesis central de este trabajo.

Dos profesores de Harvard, Steven Levitsky y Daniel Ziblatt publicaron en 2018 How Democracies Die. ${ }^{7}$ Para estos autores, la "erosión de la democracia es casi imperceptible", ${ }^{8}$ ya que "la población no cae inmediatamente en la cuenta de lo que está sucediendo". ${ }^{9}$ Las quiebras democráticas desde fines del siglo pasado y en el presente no responden a los paradigmas tradicionales, como golpes de Estado, asonadas u otras formas de usurpación violenta; al contrario, más bien se trata de procesos de desmantelamiento de las normas e instituciones democráticas a partir de la vía pacífica electoral; "en la actualidad el retroceso democrático comienza en

5 Ibidem, pp. 16 y 21.

6 Ibidem, pp. 53 y 54.

7 Traducción al español, Cómo mueren las democracias, Barcelona, Ariel, 2018.

8 Ibidem, p. 14.

9 Idem. 
las urnas", ${ }^{10}$ y precisan que "No hay tanques en las calles. La Constitución y otras instituciones nominalmente democráticas continúan vigentes. La población sigue votando. Los autócratas electos mantienen una apariencia de democracia, a la que van destripando hasta despojarla de contenido", ${ }^{11}$ pero en forma paulatina o gradual y no de un solo golpe. No obstante que su análisis está dirigido preponderantemente al caso de los Estados Unidos con la llegada de Donald Trump, lo enriquecieron con un enfoque comparativo con otros países, como Venezuela con Chávez y Maduro, Ecuador con Correa, Perú con Fujimori, Turquía con Erdogan, Hungría de Orban, Polonia con Kaczynski, entre otros; estiman que hay una suerte de patrón común en la descomposición democrática en los países de quiebre democrático, que se ajusta a cuatro indicadores: 1) el rechazo o la débil aceptación de las reglas democráticas del juego; 2) la negación de la legitimidad de los adversarios políticos; 3) la tolerancia o fomento de la violencia, y 4) la predisposición a restringir las libertades civiles de la oposición, incluidos los medios de comunicación. ${ }^{12}$ Estos indicadores subvierten lo que ellos denominan los "guardarraíles de la democracia", que en esencia identifican como reglas no escritas de la "tolerancia mutua" y la "contención institucional". ${ }^{13}$ Concluyen que en el caso de los Estados Unidos, Trump de sobra ha roto esas reglas, por lo que juzgan necesario una recomposición del sistema de partidos para cancelar su polarización actual y el desarrollo de todo un sistema de alianzas o coaliciones horizontales. ${ }^{14}$

Otro texto en la misma dirección es el de Ece Temelkuran, intitulado Cómo perder un país, ${ }^{15}$ en el que esta periodista describe el proceso de demolición democrática de Turquía a partir de la llegada al poder, también por la vía democrática, de Recep Tayyip Erdogan, mediante un proceso que abarca varios pasos, que van desde la creación de un movimiento político, con el que se trastoca la lógica y se altera el lenguaje público; pasa por el desmantelamiento gradual de los mecanismos judiciales y políticos que pueden obstaculizar la concentración del poder del gobernante autoritario, y llega hasta el diseño de una "ciudadanía" diferente y la "reconstrucción" de su propio país.

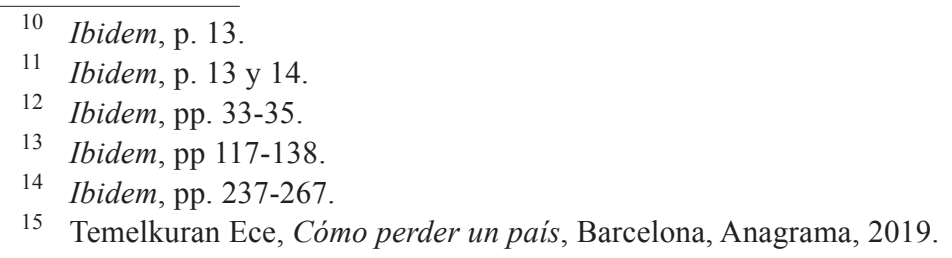


Otro interesante análisis es el que nos ofrece Yascha Mounk en The People vs. Democracy. ${ }^{16}$ Estima que vivimos en "una era de incertidumbre radical" ${ }^{17}$ en la que la democracia (el gobierno popular electo por el voto ciudadano) liberal ${ }^{18}$ (que reconoce y hace efectivos derechos y libertades fundamentales) se está descomponiendo:

de un lado, las preferencias de la gente son crecientemente iliberales: aumenta la impaciencia de los votantes con las instituciones independientes, y están cada vez menos dispuestos a tolerar los derechos de minorías étnicas y religiosas. Del otro lado, las élites están controlando el sistema político y haciéndolo insensible: los poderosos cada vez están menos dispuestos a aceptar la visión del pueblo. Como resultado, el liberalismo y la democracia, los dos elementos clave del sistema político están entrando en conflicto. ${ }^{19}$

En lugar de la democracia liberal están emergiendo dos nuevos regímenes: la democracia iliberal (democracia sin derechos) y el liberalismo indemocrático (derechos sin democracia).

En opinión de Mounk, la transformación del escenario de la democracia liberal obedece a que cambiaron las tres condiciones en las que descansaba esta forma de gobierno: 1) prosperidad económica que prevaleció entre los treinta y sesenta del siglo pasado y se revirtió con la crisis de 1985; 2) preponderancia de un grupo étnico o racial sobre los demás, que se ha modificado con la migración, y 3 ) la comunicación masiva antes controlada por elites políticas y financieras con el dominio de los medios electrónicos, ahora sustituida por la expansión comunicativa gracias al Internet y a las redes sociales.

Ésas han sido las causas del desmantelamiento de la democracia liberal. Consecuentemente, su solución está en enfrentarlas con reformas económicas nacionales e internacionales que reduzcan la desigualdad social

16 Mounk, Yascha, The People vs. Democracy - why are Freedom is in Danger \& how to sabe it, Harvard University Press, 2018. Mounk es profesor de la Universidad de Harvard.

17 Ibidem, p. 25.

18 Monk define a la democracia liberal como "un sistema político que es liberal y democrático que protege derechos individuales [como la libertad de expresión, creencia religiosa, prensa y asociación] y traduce la visión popular en política pública”, ibidem, p. 27.

19 Ibidem, p. 13.

Esta obra está bajo una Licencia Creative Commons

Atribución-NoComercial-SinDerivar 4.0 Internacional, IIJ-UNAM. 
mediante una distribución equitativa del ingreso nacional; resolver la composición multiétnica de la democracia con derechos iguales para todos, $\mathrm{y}$ finalmente hacer segura la era digital para la democracia tanto en el emisor como en el receptor de los mensajes. ${ }^{20}$ Concluye Mounk: "A pesar de que los frutos de nuestro esfuerzo permanezcan inciertos, haremos lo que podamos para salvar a la democracia liberal". ${ }^{21}$

Este diagnóstico sobre el estado de la democracia en el siglo XXI ha de complementarse con otro específico al caso de México si hemos de entender por qué la fatiga democrática también alcanza a nuestro país. "El malestar con la representación en México"22 abarca no sólo a la representación política, sino también a la social. Comprende tanto al sistema de partidos como a las organizaciones sociales, y de manera destacada a los sindicatos: "Hay una carencia de agentes de intermediación entre las instituciones y la ciudadanía, agregada en múltiples organizaciones con diferente grados de representatividad, y otra en organizaciones secuestradas por intereses diferentes a los de sus representados". ${ }^{23}$ De acuerdo con este diagnóstico, tanto la política institucional (sistema de partidos e instituciones electorales) como la no institucional (movimientos sociales y organizaciones sociales diversas) se han ido aislando y caminando por rutas y en direcciones distintas, incluso a veces opuestas, y en consecuencia:

\footnotetext{
$20 \quad$ Ibidem, pp. 16-18.

21 Ibidem, p. 266. La traducción de todas las citas de este autor son de mi autoría.

22 Título del nuevo libro de Jorge Cadena-Roa y Miguel Armando López Leyva editado por la UNAM, el Instituto de Investigaciones Sociales y el Centro de Investigaciones Interdisciplinarias en Ciencias y Humanidades, Ficticia Editorial, México 2019. La tesis central de esta obra consiste en argumentar y demostrar que la democratización en México no rompió con el autoritarismo anterior, sino que ha mantenido intercalados a enclaves o "lastres" autoritarios, que hoy en día generan un extendido malestar entre los representados por las recurrentes corrupción, impunidad y violación a los derechos humanos que arrastró el régimen anterior. Véase sobre todo la "Introducción: problemas actuales de la representación social y política en la democracia mexicana" de los dos autores citados pp. 21-51, y el capítulo II “¿En qué momento se malogró la representación en México” de Jorge Cadena Roa, pp. 123-159. Cadena Roa es doctor en sociología por la Universidad de Wisconsin-Madison, investigador titular del CEIICH_UNAM y miembro de la Junta de Gobierno de la UNAM. López Leyva es doctor en ciencias sociales con especialidad en ciencia política por la Facultad Latinoamericana de Ciencias Sociales, y actualmente director del Instituto de Investigaciones Sociales de la UNAM.
}

23 Ibidem, p. 40. 
el alejamiento entre los intereses de los representantes y las demandas de los ciudadanos es uno de los mayores daños que puede hacérsele a una democracia, porque deja de funcionar como un "gobierno del pueblo, por el pueblo y para el pueblo", como dijera Lincoln en su célebre discurso en Gettysburg el 19 de noviembre de 1863, y se transforma en un gobierno de los partidos, por los políticos y para ellos y sus socios, y el sistema económico en un capitalismo de cuates y tráfico de influencias (crony capitalism). ${ }^{24}$

La llamada "democracia participativa", que busca un involucramiento directo de la ciudadanía en la determinación de la agenda pública, y no a través de sus representantes, es una respuesta a esos padecimientos críticos de la democracia representativa. México, aún antes del inicio de la presente administración, y sobre todo con motivo de la Asamblea Constituyente que dio a la Ciudad de México (CdMx) su primera Constitución, no ha estado exento de esta tendencia. En la nueva carta magna de la CdMex se incluyó un catálogo bastante amplio de figuras de democracia directa, a la que se reconoce como "derecho y un deber de participar en la resolución de problemas y temas de interés general en el mejoramiento de las normas que regulan las relaciones en la comunidad, a través de los mecanismos de democracia directa y participativa reconocidos por esta Constitución" (artículo 25.A.1)

Pero el problema de la crisis de la democracia representativa no puede entenderse sólo por las condiciones político-sociales actuales. Deseo agregar a mi argumento central antes expuesto, que el problema presente del desencanto democrático tiene una raíz genético-estructural más antigua. Para decodificarla he incluido a dos autores clásicos: Benjamin Constant (siglo XIX), ${ }^{25}$ y Hans Kelsen (XX),${ }^{26}$ quienes en su tiempo anticiparon las

24 Ibidem, p. 41.

25 Benjamin Constant (1767-1830), cuya vida transcurre entre la segunda mitad del siglo XVIII y la primera parte del XIX, fue un filósofo y político francés de origen suizo, testigo de la Revolución en Francia y el Imperio de Napoleón, por lo que su pensamiento político es una suerte de puente entre dos grandes épocas históricas del antiguo régimen y la modernidad. Se ocupó profusamente del tema de la representación política tanto en su obra Los principios de la política aplicable a todos los gobiernos representativos como en su célebre discurso ante el Atheneé Royal de Paris: "La libertad de los antiguos comparada con la de los modernos".

26 Hans Kelsen (1881-1973), de origen austriaco, fue un jurista y filósofo del derecho y la política. Profesor de derecho en la Universidad de Viena, y al final de su vida en Berkeley, California, Elaboró la nueva Constitución de Austria y fue miembro vitalicio 
limitaciones de la democracia representativa con un enfoque político el primero y jurídico el segundo. Constant activó una certera alarma desde 1819 sobre las consecuencias de dejar el sistema representativo en manos de los políticos. Casi un siglo después, en 1925, Hans Kelsen publicó su Teoría general del Estado, con una crítica a la representación del pueblo por el Parlamento, a la que califica como "una ficción". A estos autores he agregado otro reciente: el argentino Roberto Gargarella, ${ }^{27}$ quien en 1997 escribió Crisis de la representación política, en donde elabora una interesante crítica del sistema representativo de carácter histórico-sociológico, basado en un análisis del diseño a cargo del constituyente de los Estados Unidos en 1787.

Hasta ahí se ha desarrollado una parte de la hipótesis central: la crisis de la democracia representativa. Para completarla con la segunda, la respuesta de la democracia participativa, el artículo incursiona en el análisis de diversas concepciones de la democracia: representativa, directa, participativa y radical, a partir de las cuales se discute la idea de una integración con los elementos de las distintas variantes democráticas, visualizando una nueva forma de incluir a los ciudadanos en la toma de decisiones. Finalmente, se cierra con algunas reflexiones a manera de conclusión, acerca del futuro de la participación democrática y su dificultad para asimilarla al sistema representativo vigente, como una suerte de contraargumentación a la hipótesis fundamental del artículo.

\section{LAS CRÍTICAS A LA DEMOCRACIA REPRESENTATIVA}

Sobre el problema genético de la democracia representativa, fue el ginebrino Benjamin Constant en su famosa alocución en el Athenée Royale de Paris en 1818, intitulada "Discurso sobre la libertad de los antiguos com-

del Tribunal Constitucional austriaco diseñado por él mismo para la defensa de la supremacía constitucional. Autor de La teoría pura del derecho, en la que evita el sincretismo metódico con base en la filosofía de Kant, fue también autor de la Teoría general del Estado, estructurada con un enfoque estático y otro dinámico del Estado identificado con el derecho.

27 Abogado, jurista y sociólogo nació en Buenos Aires, Argentina, en 1964, y actualmente es profesor en la Universidad Torcuato Di Tella y en la Universidad de Buenos Aires. Interesado en buscar alternativas a temas como la pena de muerte y, sobre todo, al sistema de representación elitista con base en una democracia deliberativa en donde prevalezca el debate entre el Estado y la población mayoritaria. 
parada con la de los modernos", ${ }^{28}$ quien lo advirtió al explicar la gran diferencia entre la democracia directa ejercida por los antiguos, que consistía en participar ${ }^{29}$ en las deliberaciones en la plaza pública sobre diversos asuntos de interés colectivo, sobre todo la guerra y la paz, y la democracia representativa de los modernos, cuya sociedad se basaba en el comercio y en la búsqueda de la riqueza personal, dejando en sus representantes la atención de los asuntos públicos.

Es importante recordar ahora ese discurso de Constant, porque a más de un siglo de distancia pudo prever las consecuencias negativas de dejar la política en manos de los políticos-representantes, anticipando con ello el escenario actual:

El peligro de la libertad moderna es que, absortos en disfrutar nuestra independencia privada y en la búsqueda de nuestros intereses particulares, debemos renunciar muy fácilmente a participar en el ejercicio del poder político. Los poseedores de la autoridad sólo están ansiosos de animarnos a obrar así. ${ }^{30}$

A más de un siglo de este pronóstico por el que Constant alertaba sobre las consecuencias del alejamiento del ciudadano de la política, dejándola en manos de sus representantes, debido a su enajenación económica, es en gran medida lo que estamos viviendo: la crisis de la democracia representativa, por la que el ciudadano no se siente, válgase la redundancia, representado por sus representantes, y, por lo mismo, está buscando nuevos y más efectivos canales de participación política.

Quien con mayor claridad expuso el problema jurídico-estructural de la democracia representativa, como una ficción de la representación del pueblo por el Parlamento o el Congreso, fue el jurista vienés Hans Kelsen, al señalar que "La esencia de la democracia representativa - en contradicción con su propio nombre — ${ }^{31}$ consiste en que no es el pueblo sino el par-

28 Véase mi análisis del pensamiento político de Benjamín Constant, y sobre todo su discurso ante el Athenée Royale, en Rabasa Gamboa Emilio, el capítulo "La representación política en el siglo XVIII", 1994, pp. 48-84.

29 Si bien una participación limitada a los ciudadanos varones mayores de edad.

30 Constant, op. cit., p. 78.

31 Contradicción, porque etimológicamente la democracia se entiende como demos=pueblo y kratos= gobierno o poder; esto es, gobierno del pueblo, pero democracia representativa significa gobierno de los representantes, no del pueblo. 
lamento [o congreso] el llamado a legislar, pudiendo realizar esta función con toda independencia del primero". ${ }^{32}$

Para fundamentar su argumento, Kelsen sostiene que no existe un acto jurídicamente vinculante entre la voluntad del elector y la del elegido como su representante por el que pudiera afirmarse que lo que quiere el segundo corresponde exactamente a lo que desea el primero. Y es precisamente esa ausencia de una relación legalmente vinculante lo que permite a los representantes desligarse de los representados, de tal suerte que aquéllos no se encuentran jurídicamente obligados a escuchar y atender las necesidades y reclamos de éstos, y traducirlos en legislación. Consecuentemente, y ante la ausencia de esa vinculación jurídica, los representantes atienden a sus propios intereses o los de su partido.

\section{La argumentación de Roberto Gargarella}

Con base en el diseño del sistema de representación de los Estados Unidos, Gargarella afirma que ya desde antes del Constituyente de Filadelfia había "conflictos contrainstitucionales" debido a la "presencia de instituciones poco receptivas de las demandas del electorado", ${ }^{33}$ sobre todo en las legislaturas estatales, como el caso de Rhode Island en Nueva Inglaterra. Posteriormente, los integrantes de la Convención Constituyente "defendieron el sistema representativo como un medio óptimo para separar a la ciudadanía del ejercicio directo del poder. La democracia directa, en este sentido, no solamente era difícil de practicar, sino [fundamentalmente] indeseable". ${ }^{34}$ Consecuentemente, diseñaron "un sistema en el que las mayorías quedaban inhabilitadas para deliberar de por sí, y prácticamente incapacitadas para ejercer un control efectivo sobre el gobierno". ${ }^{35}$ Este sesgo "contramayoritario" abrió el camino para un sistema representativo de corte elitista que facilitaría

el arribo al poder de individuos de clase alta; y estaría dirigido en tal sentido a la protección de la minoría de aquellos que Hamilton denominara abiertamente "los ricos y bien nacidos" ${ }^{36}$ Esto "permitió que el sistema político

\footnotetext{
Kelsen, Hans, 1965, p. 403.

33 Gargarella, op. cit., 1997, p. 13.

34 Ibidem, p. 47.

35 Idem.

36 Ibidem, p. 48.
} 
resultase más sensible a las presiones privadas que a las presiones públicas, separando a la ciudadanía de sus representantes. ${ }^{37}$

El desapego del ciudadano hacia la política, más interesado en los asuntos privados (Constant), la ausencia de una relación jurídicamente vinculante entre el representante y el representado (Kelsen) y un sistema representativo diseñado para favorecer a una minoría en detrimento de la mayoría (Gargarella), permiten entender mejor la crisis de la democracia representativa, que en el caso de México se acentúa por el malestar extendido con la representación política y social (Cadena Roa). Pasemos ahora al análisis de la segunda parte de la hipótesis central: la respuesta de la democracia representativa, para lo que es necesario detenernos brevemente en las distintas formas de democracia.

\section{TIPOLOGÍA DE LA DEMOCRACIA}

A) La democracia representativa deriva del paradigma liberal, que tiene como principio básico el asentamiento de la soberanía popular; esto es, la elección del gobierno por el pueblo y el reconocimiento de sus derechos y libertades. El consentimiento de los gobernados es otorgado a través de elecciones competitivas y periódicas, donde los individuos pueden aceptar, rechazar, y sólo hasta cierto punto controlar a sus dirigentes. ${ }^{38}$

En esta visión de la democracia, el ciudadano puede llegar a tener un papel pasivo si su participación se reduce exclusivamente a votar en las elecciones, con la finalidad de elegir a una minoría supuestamente capaz de gobernar efectiva y coherentemente. ${ }^{39}$

B) La democracia participativa plantea el involucramiento ciudadano en el proceso de toma de decisiones públicas mediante mecanismos de democracia directa, como la consulta e iniciativa popular, el referéndum, el plebiscito, la revocación de mandato, etcétera, Incluye además a la democracia deliberativa, entendida como espacios de deliberación pública (parlamento, tribunales, la prensa y la opinión pública en redes sociales), y finalmente, la democracia participativa en sentido estricto, con la finalidad

\footnotetext{
37 Ibidem, pp. 78 y 79.

38 Viejo et al., 2009, p. 30.

39 Walker 1966.
} 
de que la ciudadanía se involucre en la formulación, planificación y/o gestión de determinadas políticas públicas, como el presupuesto participativo.

Los argumentos a favor de estas formas de gobierno son:

1) Los ciudadanos son los que mejor conocen sus problemas, y serán más eficaces en la toma de decisiones que los técnicos del gobierno,

2) Se desarrolla el sentido de comunidad, el interés en la cosa pública y la confianza en las instituciones.

C) La democracia radical, que busca dotar a la ciudadanía de capacidades realmente iguales de participación. Se reconoce que nacemos con desigualdades, por lo que las políticas públicas no se deben conducir por principios homogéneos, sino por el reconocimiento de las diferencias que hace indispensable las estrategias de acciones afirmativas

Frente al problema que representa la crisis de la democracia representativa en la actualidad, quizá podría configurarse una teoría que sirviera de fundamento a una nueva praxis política integrando y fusionando algunos de los elementos de cada uno de los tres tipos de democracia antes expuestos, a manera de síntesis, con la finalidad de proporcionar una sólida base y fundamento de la participación ciudadana en el contexto actual del extendido descontento con el sistema representativo.

De la democracia representativa son desde luego asimilables los derechos políticos activos y pasivos, y en general los derechos fundamentales que ha expandido el neoconstitucionalismo. ${ }^{40}$ De la democracia participativa se incluirían las figuras clásicas de las formas de participación ciudadana, como el referéndum, el plebiscito, la consulta e iniciativa popular y la revocación de mandato, al mismo tiempo que se aseguren los espacios de la deliberación pública tanto tradicionales como los nuevos, producto de las nuevas tecnologías de la comunicación e información que generan redes sociales. Más complicados resultan los elementos de la democracia radical por la premisa de la igualdad ciudadana, que requiere la efectiva participación política.

Son cinco los principios de la participación ciudadana que atienden las desigualdades de inicio entre ciudadanos a las que se refiere la democracia radical: descentralización del poder en el gobierno, facilitar la moviliza-

40 Al respecto, véase "Neocostitucionalismos", especialmente el prólogo de Miguel Carbonell, pp. 9-12, el artículo de Luigi Ferrajoli, "Pasado y futuro del Estado de derecho", pp. 13-30, y "Los derechos fundamentales en el Estado constitucional democrático" de Robert Alexy, pp. 31-48, Edición de Miguel Carbonell, México, UNAM-Trotta, 2006. 
ción social, facilitar la discusión de temas, promover las redes y alianzas de ciudadanos, fortalecer la vigilancia de las acciones del gobierno.

Antes de profundizar en las modalidades de la democracia participativa en nuestro país, resulta importante considerar las experiencias de otros países que han intentado introducir medios de participación de democracia directa o radical en sus esquemas de la democracia representativa, en particular los casos de Venezuela, Ecuador y Bolivia, conocidos como "el nuevo constitucionalismo latinoamericano".

De acuerdo con Guadalupe Salmorán, ${ }^{41}$ el nuevo constitucionalismo latinoamericano es un fenómeno que se dio a principios del siglo XXI con la aprobación de nuevas Constituciones en Venezuela, Ecuador y Bolivia, derivadas de procesos de movilización popular, que culminaron en la convocatoria a asambleas constituyentes y referéndums populares para aprobar los textos constitucionales definitivos. El calificativo de "nuevo" proviene de la crítica que hicieron al viejo constitucionalismo, que en su opinión refleja los intereses elitistas de los partidos políticos liberales, y no los del pueblo. Por esta razón, los nuevos textos constitucionales buscaron incorporar mecanismos para asegurar la voluntad popular por encima de los controles contramayoritarios. Para ello reformaron su Constitución e insertaron en ella mecanismos como el plebiscito, el referéndum, la revocación del mandato, la elección directa de los jueces, consultas ciudadanas, iniciativas de ley a propuesta de los ciudadanos, entre otros. Algunas otras características comunes de estas Constituciones son su extensión, la incorporación de ideologías diversas y cosmovisiones indígenas, rigidez para ser modificadas, reconocimiento de nuevos derechos individuales y colectivos, cuyo objetivo sería reducir la exclusión y desigualdad social (derechos económicos, sociales, culturales y ambientales o DESCA), más facultades al Estado en materia económica.

El nuevo constitucionalismo latinoamericano no está exento de críticas. Respecto a la inclusión de los DESCA y de las ideologías y cosmovisiones indígenas, se señala una posible apertura de espacios de discrecionalidad para su interpretación, así como la reducción de la certeza y seguridad jurídica para los ciudadanos. Otra crítica que se ha hecho a los mecanismos

41 Investigadora del Instituto de Investigaciones Jurídicas de la UNAM; doctora en Teoría Política por la Universidad de Turín, Italia. Profesora en el posgrado de Derecho y la Facultad de Ciencias Políticas de la UNAM. Se ha especializado en temas electorales, el populismo y el nuevo constitucionalismo latinoamericano, particularmente en Venezuela, Ecuador y Bolivia. 
de la democracia directa es que, en el caso de los referéndums y consultas populares, quien formula las preguntas generalmente es el Poder Ejecutivo, y la consulta sólo se limita a que los electores contesten con una simple afirmación o negación. En estos procesos, no necesariamente se incluye un espacio deliberativo previo que se da en los parlamentos, en donde se discuten las diferentes posiciones antes de hacer cambios normativos. Además, podría estarse rompiendo el principio de división de poderes, ya que al ser el Ejecutivo el que formula las preguntas, es este poder y no el Legislativo el que, de hecho, está legislando, aun cuando estas preguntas requieran ser aprobadas por las cortes y sometidas a votación por los ciudadanos. Sin embargo, cabe mencionar que no siempre los electores han votado de manera afirmativa a la consulta del Ejecutivo en los plebiscitos y refréndums a los que se les ha convocado. Éste fue el caso de la propuesta de reforma constitucional en Venezuela de 2017, y la propuesta de reelección consecutiva del presidente en Bolivia en 2016. Asimismo, la elección directa de los jueces y la posibilidad de que el Legislativo les revoque su mandato han sido criticadas por la posibilidad de que los órganos jurisdiccionales queden sometidos a la mayoría política que controle al Ejecutivo o al Legislativo. ${ }^{42}$

Con este marco comparativo, veamos ahora las distintas formas de democracia directa que se han venido desarrollando en nuestro país.

\section{MODALIDADES DE DEMOCRACIA DIRECTA EN MÉXICO}

En México, en los últimos años se han dado ya varios pasos en el camino de la democracia participativa, como son las figuras de las candidaturas electorales independientes, la encuesta pública, la iniciativa popular (también conocida como iniciativa ciudadana), el referéndum, el plebiscito y la revocación del mandato. A continuación se presenta una breve exposición de las mismas, lo que da una idea general del avance de nuestra legislación en esta materia, ${ }^{43}$ y nos permite identificar mejor las facilidades (fortale-

42 Salmorán, Guadalupe, 2016, pp. 1-23.

43 Que por muchos años estuvo ausente o dormida ante la preeminencia o casi hegemonía de los mecanismos de la democracia representativa, en auge debido a las reformas constitucionales en materia político-electoral a partir de 1977, descritas ampliamente en mi libro Las reformas constitucionales en materia político-electoral (edición bilingüe del 
zas) y dificultades (debilidades) para su adecuada y armónica integración constitucional en nuestro país.

\section{Las candidaturas independientes}

Se constitucionalizaron en agosto de 2012 en el artículo 35, fracción II, como un derecho político pasivo del ciudadano para

poder ser votado para todos los cargos de elección popular teniendo las calidades que establezca la ley. El derecho de solicitar el registro ante la autoridad electoral, corresponde a los partidos políticos así como a los ciudadanos que soliciten su registro de manera independiente y cumplan con los requisitos, condiciones y términos que determine la legislación. ${ }^{44}$

Esta figura permite la participación electoral directa de los ciudadanos, sin intermediación de los partidos políticos.

\section{La consulta popular}

Establecida en el artículo 35, fracción VIII, mediante una adición constitucional en $2012^{45}$ y reformada en 2014, concede el derecho a los ciudadanos mexicanos a votar en las consultas populares sobre temas de trascendencia nacional, en los términos y condiciones que establece el mismo texto de la Constitución. ${ }^{46}$

La Constitución de la CdMx, en el artículo 25, incisos E y F, establece dos modalidades de la misma figura: la consulta ciudadana y la consulta

Instituto de Investigaciones Jurídicas de la UNAM y la ONU, publicado en 2012). Pero a partir de las reformas constitucionales de 2012, y sobre todo con la nueva Constitución de la CdMx, en 2018, los mecanismos de la democracia directa han cobrado especial atención en el debate político nacional.

44 Para un análisis detallado de las candidaturas independientes véase Figueroa Ávila, Enrique, 2019.

$45 \mathrm{Su}$ antecedente es la reforma y adición de 1983 al artículo 26, tercer párrafo, que estableció la consulta popular, pero exclusivamente para el sistema nacional de planeación democrática.

46 Incisos 1 a 7 de la fracción VIII del artículo 35 constitucional, que indican quién puede organizar la encuesta (Congreso, presidente, legisladores y ciudadanos en el número que se indica), términos para que la consulta sea vinculante, materias o temas no susceptibles de consulta y la intervención del INE. 
popular, si bien la diferencia entre una y otra en cuanto al objetivo de estos instrumentos es bastante nebulosa. La primera es el derechos de las y los ciudadanos a ser consultados sobre "cualquier tema que tenga impacto trascendental en los distintos ámbitos temáticos o territoriales de la Ciudad". La segunda es también el derecho a ser consultados "sobre temas de trascendencia de la Ciudad". Aquélla por cualquier autoridad, y ésta, por el Congreso de la Ciudad, además de un mayor número de requisitos y limitantes en la consulta popular que en la ciudadana. ${ }^{47}$

\section{La iniciativa popular ${ }^{48}$}

Dispuesta en el artículo 71, fracción IV, mediante reforma de 2012, concede el derecho a los ciudadanos en un número equivalente, por lo menos, al cero punto trece por ciento de la lista nominal de electores en los términos que señalen las leyes, para iniciar leyes o decretos.

En la Constitución de la CdMex se denomina "iniciativa ciudadana" al derecho de las y los ciudadanos a iniciar leyes y decretos, así como reformas a la Constitución. ${ }^{49}$ La reforma constitucional no está contemplada para la iniciativa popular en la Constitución federal.

\section{El referéndum}

Introducido en la Constitución junto con la iniciativa popular mediante la reforma político-electoral de $1977^{50}$ en el artículo 73, fracción VI, base 2a., sólo para el entonces Distrito Federal, en los siguientes términos: "Los ordenamientos legales y los reglamentos que en la ley de la materia se determinen, serán sometidos al referéndum y podrán ser objeto de la iniciativa popular, conforme al procedimiento que la misma señale". El referéndum nunca tuvo aplicación en la práctica en el Distrito Federal, y fue derogado en 1987.

\footnotetext{
47 Compárense los numerales 1, letras a) a f), y 2, de la figura de la consulta popular con los numerales 1 y 2 de la consulta ciudadana, ambas en el artículo 25, incisos E y $\mathrm{F}$, de la Constitución de la CdMex.

48 Introducida en la Constitución mediante reforma de 1977.

49 Artículo 25, inciso B, numerales 1 a 5, que regulan los términos y requisitos de este derecho de los ciudadanos habitantes de la Ciudad de México.

50 Rabasa Gamboa, Emilio, 1998, pp. 147-170.
} 
Actualmente es retomado en el capítulo II, artículo 25, Democracia directa, inciso C, de la nueva Constitución Política de la CdMex, en estos términos: "Se reconoce el derecho ciudadano a aprobar mediante referéndum las reformas a esta Constitución conforme a lo establecido en el artículo 69 de esta Constitución, así como a las demás disposiciones normativas de carácter general que sean competencia del Congreso de la Ciudad de México". ${ }^{51}$

Como puede observarse, la nueva Constitución de la CdMex estableció una figura del referéndum con un ámbito de validez material más amplio, que la que en su momento incluyó la reforma a la Constitución federal de 1977, ya que ésta lo limitó a los ordenamientos legales y reglamentos, en tanto aquélla lo extendió a las reformas a la Constitución de la CdMex y las normas generales.

Por su parte, las Constituciones de Tabasco (artículo 8 bis) y Zacatecas (artículo 45) ya contenían desde hace tiempo esta figura que han desarrollado en su respectivos textos ampliamente.

\section{El plebiscito}

No ha figurado en la Constitución federal, pero sí fue incorporado en la Constitución de la CdMex en el artículo 25, inciso D, en los siguientes términos: "Las y los ciudadanos tienen derecho a ser consultados en plebiscito para aprobar o rechazar decisiones públicas que sean competencia del Poder Ejecutivo de la Ciudad o de las alcaldías". Las materias de derechos humanos, penal, tributaria y fiscal no podrán ser objeto de plebiscito.

Las Constituciones de Tabasco (artículo 8 bis) y Zacatecas (artículo 46) contienen estas figuras de tiempo atrás, y las han desarrolla ampliamente en sus respectivos textos.

\section{La revocación de mandato}

Como se asentó anteriormente con la crítica de Hans Kelsen, la democracia representativa no incluye en la figura de la representación del

51 En el citado precepto se incluyen los términos y condiciones de este derecho y la materia (derechos humanos, penal o tributaria) excluida del referéndum. 
pueblo por el Congreso o parlamento la relación vinculante entre el representante y el representado por medio de la cual éste pueda exigirle determinada conducta a aquél. El representante, una vez electo, actúa con total independencia del representado. Sin embargo, la democracia directa ha desarrollado una figura que le permite a este último retirar o revocar el mandato que confirió en el acto de la elección. La legislación no señala las causas por las que el ciudadano puede revocar ese mandato; simplemente expresa que "Las y los ciudadanos tienen derecho a solicitar la revocación del mandato de representantes electos cuando así lo demande al menos el $10 \%$ de las personas inscritas en la lista nominal de electores del ámbito respectivo" (artículo 25, inciso G, 1 de la Constitución de la CdMex). Y agrega que "la consulta para la revocación de mandato sólo procederá una vez, cuando haya transcurrido al menos la mitad de la duración del cargo de representación popular de que se trate" (artículo 25, G2, de la Constitución de la CdMex).

En el ámbito federal esta figura fue objeto de un intenso debate dentro y fuera del ámbito legislativo y de los partidos políticos, debido fundamentalmente a la fecha en que se pretendía llevar a cabo la consulta respectiva. ${ }^{52} \mathrm{~A}$ este respecto, la Constitución de la CdMex es muy clara al prohibir que, con excepción de la consulta popular, ninguna de las figuras de la democracia directa "podrá llevarse a cabo cuando exista proceso electoral" (artículo 25, inciso F, numeral 2). En otras palabras, la Constitución local es contundente en cuanto a la preservación del proceso electoral libre de cualquier medida o instrumento que pudiera contaminar la elección y afectar su resultado.

52 Finalmente, se acordó que se llevaría a cabo después de concluida la elección intermedia, a efecto de no contaminarla con un proceso político distinto por el que se cruzarían el ejercicio principal de la democracia representativa como es la elección, con esta modalidad de democracia directa. El artículo transitorio cuarto de la reforma del 20 de diciembre de 2019 establece que el periodo para la recaudación de firmas para la solicitud de revocación de mandato del presidente de la República electo para el periodo 2018-2024 comenzará en el mes de noviembre y hasta el 15 de diciembre de 2021, y que la petición correspondiente deberá presentarse dentro de los primeros quince días del mes de diciembre de 2021. Si la solicitud es procedente, el INE emitirá la convocatoria dentro de los veinte días siguientes al vencimiento del plazo para la presentación de la solicitud. La jornada de votación será a los sesenta días de expedida la convocatoria. Esto quiere decir que la jornada ocurriría en los primeros meses de 2022, ya lejos de la elección intermedia. 
La reforma constitucional de 2019

E1 20 de diciembre de 2019 se publicó en el Diario Oficial de la Federación la reforma a nueve artículos de la Constitución federal en materia de consulta popular y revocación de mandato, lo que confirma la hipótesis de este trabajo sobre la presencia actual y el avance de la democracia directa en relación con la crisis de la democracia representativa.

\section{Consulta popular}

Respecto de la consulta popular, se agregaron, en adición a los temas de trascendencia nacional, los de trascendencia regional para una o varias entidades federativas. A la lista de asuntos que no podrán ser objeto de consulta popular se adicionaron los tratados internacionales sobre derechos humanos y las garantías para su protección, ${ }^{53}$ la permanencia o continuidad en el cargo de los servidores públicos de elección popular, ${ }^{54}$ el sistema financiero, el presupuesto de egresos y las obras de infraestructura en ejecución.

La reforma amplió la función del INE en la consulta popular, al incluir atribuciones de promoción de la participación ciudadana en la misma de manera imparcial, evitando influir en la preferencia ciudadana. De manera

53 Adición innecesaria, toda vez que ya existía la prohibición de restringir los derechos humanos reconocidos en la Constitución, y el artículo 1o. incluye a los tratados internacionales.

54 Esta prohibición deberá interpretarse de conformidad con lo dispuesto por la parte de la reforma que se comenta en los artículos 81,116 y $122 \mathrm{~A}$, III, que por vez primera introducen la revocación de mandato, respectivamente, del presidente de la República, los gobernadores de los estados y el jefe de gobierno de la Ciudad de México. En el caso del titular del Ejecutivo federal, el proceso será conducido por el INE, pero no mediante consulta popular, sino mediante votación libre, directa y secreta de los ciudadanos y ciudadanas inscritos en la lista nominal (artículo 35, 6.o. y 7o., fracción IX). En los otros dos casos será regulado por las Constituciones locales y de la CdMex. De cualquier manera, es discutible si la revocación de mandato aun mediante sufragio universal y directo entraña o no una consulta sobre la permanencia o continuidad en el cargo de los servidores públicos de elección popular objeto de esta nueva figura constitucional (presidente, gobernadores y jefe de Gobierno de la CdMex). En caso de ser afirmativa la respuesta, estaríamos ante una contradicción constitucional y en el mismo precepto. Afortunadamente, también en el artículo 35 (fracción VIII, numeral 3) se estableció que será la Suprema Corte de Justicia de la Nación la que resuelva sobre la constitucionalidad de la materia de la consulta previa a la convocatoria que realice el Congreso de la Unión. 
acertada se modificó la fecha para realizar la consulta, que antes era el mismo día de la jornada electoral, y ahora será el primer domingo de agosto (numeral 5o.).

\section{Revocación de mandato ${ }^{55}$}

En cuanto a la revocación de mandato, se agregó la fracción IX al artículo 35 como un derecho ciudadano, que incluye todo el procedimiento para llevarlo a cabo a cargo del INE: ${ }^{56}$ no obstante, el Congreso emitirá la ley reglamentaria correspondiente. ${ }^{57}$ Pero esta figura también fue agregada en el artículo 36 como una obligación del ciudadano, con lo que al igual que votar en las elecciones queda con un doble carácter de derecho y obligación..$^{58}$

En el artículo 41, referente a las atribuciones del INE, se agregaron las correspondientes a la implementación de la revocación de mandato y la posibilidad de celebrar convenios con las entidades federativas para

55 Curiosamente, el concepto no lo define la reforma en el cuerpo normativo principal, sino en el artículo tercero transitorio: "Para efectos de la revocación de mandato a que hace referencia la Constitución tanto a nivel federal como local, deberá entenderse como el instrumento de participación solicitado por la ciudadanía para determinar la conclusión anticipada en el desempeño del cargo a partir de la pérdida de la confianza".

56 Como elementos constitutivos de esta figura cabe resaltar que sólo procede a petición ciudadana ( $3 \%$ de la lista nominal y por lo menos en diecisiete entidades federativas), ocurrirá sólo en una sola ocasión y tres meses después de la conclusión del tercer año del periodo constitucional, mediante votación libre, directa y secreta; su validez queda sujeta a que haya participado por lo menos el $40 \%$ de los ciudadanos inscritos en la lista nominal de electores, y por mayoría absoluta, el INE tendrá a su cargo la organización, el desarrollo y cómputo de la votación, y sus resultados podrán ser impugnados ante la Sala Superior del Tribunal Electoral del Poder Judicial de la Federación. Este órgano realizará el computo final después de resolver impugnaciones, con lo que estamos en presencia de dos cómputos, el del INE y el del Tribunal. Finalmente, se incluyen una serie de candados para garantizar la imparcialidad de la votación, como la realización de propaganda con recursos públicos y la difusión de propaganda gubernamental, salvo educación, salud y protección civil (artículo 35, fracción IX).

57 Para lo que cuenta con 180 días, seis meses, según lo indica el artículo segundo transitorio de la reforma.

58 Y en todo caso corresponderá a la ley reglamentaria que emita el Congreso de la Unión la que determine si incluye o no sanciones en el caso de que no se cumpla con esa obligación. De no hacerlo, quedaría como una obligación incompleta o imperfecta, ya que la obligación es la conducta contraria al acto antijurídico como supuesto de una sanción. En otras palabras, quien incumple con una obligación (como pagar impuestos) comete un ilícito, que trae como consecuencia una sanción. 
ejecutar esta figura en caso de que decidan no hacerlo los organismos públicos locales. Finalmente, se establece que el sistema de impugnación para asegurar la constitucionalidad y legalidad de los actos y resoluciones electorales se extenderá a los procesos de consulta popular y revocación de mandato.

Fundamental fue la parte de la reforma sobre revocación de mandato al artículo 81, que por vez primera en la historia de México consigna que "el cargo de presidente de los Estados Unidos Mexicanos puede ser revocado", y en caso de que proceda la revocación ocupará la titularidad del Ejecutivo Federal quien ocupe la presidencia del Congreso, ${ }^{59}$ a fin de que este órgano legislativo en no más de treinta días designe a quien concluya el periodo constitucional. ${ }^{60}$

Por su parte, los artículos 116 y 122, también objeto de esta reforma, extienden respectivamente la revocación de mandato a los gobernadores de los estados y jefe de Gobierno de la CdMex, dejando a sus correspondientes Constituciones ${ }^{61}$ la precisión de las normas que regularán estos procesos. $^{62}$

59 Es importante observar que la Constitución no contiene la figura de "Presidente del Congreso", sino únicamente de cada una de sus Cámaras. Es la Ley Orgánica del Congreso la que señala en su artículo 5o. lo siguiente: "Cuando el Congreso sesione conjuntamente lo hará en el reciento que ocupe la Cámara de Diputados y el presidente de ésta lo será de aquél". De modo que en caso de revocación de mandato ocupará temporalmente la presidencia de la República el presidente de la Cámara de Diputados durante los treinta días con que cuenta el Congreso para designar a quien concluya el mandato constitucional, en los términos de la reforma al artículo 81 constitucional.

60 Mediante esta disposición, el sistema constitucional mexicano inserta un elemento que corresponde típicamente al sistema constitucional del parlamentarismo, como es el caso de que el jefe del gobierno (y en México también jefe del Estado) emerge del Poder Legislativo y no del voto popular directo, como es el caso, por ejemplo, de las Constituciones de Gran Bretaña, Italia, España y Alemania en Europa, para sólo mencionar algunas, y, consecuentemente, se aparta del sistema constitucional presidencial fundado por los Estados Unidos en 1787.

61 Con base en esta nueva disposición constitucional federal, deberá ser ajustada la Constitución de la CdMex, porque en la parte correspondiente a la revocación de mandato (artículo $25 \mathrm{G}$ ), esta última carta contempla esta figura para "representantes electos", sin especificar si esto incluye no sólo a los alcaldes, sino también al jefe del Gobierno de la CdMex. Por su parte, el artículo 32 de la Constitución local, relativo a la Jefatura de Gobierno, no incluye (como ahora el numeral 81 de la Federal) la figura de la revocación del mandato para el o la titular de la jefatura.

62 Las entidades federativas cuentan con dieciocho meses siguientes a la entrada en vigor del decreto de la reforma, para garantizar el derecho ciudadano a solicitar la revo- 
Con todas estas figuras de democracia directa, México se suma a las cincuenta naciones en el mundo en que la legislación ha incorporado diversos instrumentos de democracia participativa. En Latinoamérica es el caso de Argentina, Bolivia, Ecuador, Costa Rica, entre otros países. Debe decirse, sin embargo, que su uso ha sido muy limitado en el hemisferio continental. La consulta a la ciudadanía sobre temas fundamentales es el mecanismo de democracia más utilizado en el mundo: 121 países contienen disposiciones al respecto.

En México, la nueva Constitución de la CdMex es sin duda la norma más avanzada en la materia de la democracia participativa. ${ }^{63}$ Todo un capítulo (II) está dedicado a las figuras de la democracia directa que se han comentado, las de la democracia participativa, que incluye la gestión, evaluación y control de la función pública, además del presupuesto participativo (artículo 26, incisos A y B), e incluso también de la democracia representativa, que incluye a las candidaturas sin partido (artículo 27, inciso A) y a los partidos políticos (artículo 27, inciso B). Varias legislaturas de otras entidades federativas incluyen algunas de estas figuras, señaladamente Tabasco y Zacatecas, pero ninguna con la diversidad, amplitud y profundidad que la Constitución de la CdMex, con la que se ha buscado equilibrar las carencias de la democracia representativa con la democracia directa y participativa, al menos en la capital del país y nueva entidad federativa.

\section{CONCLUSIONES}

En este trabajo se ha desarrollado la hipótesis de que el actual desencanto ciudadano con la democracia representativa ha provocado como respuesta el surgimiento de diversas figuras de la democracia participativa o directa citando los casos de Bolivia, Venezuela y Ecuador, y profundizando en las modalidades de México.

Adicionalmente, se ha propuesto la integración de elementos de los diversos tipos de democracia: representativa, participativa y radical, a mane-

cación de mandato y, consecuentemente, reformar sus respectivas Constituciones. El artículo sexto transitorio que establece ese derecho también fija los lineamientos generales para su implementación.

63 Salvo por lo que se refiere a las figuras de la consulta popular y revocación de mandato, conforme a la reforma del 20 de diciembre del 2019 a la Constitución federal, ampliamente comentada en este trabajo. 
ra de una síntesis para una gobernanza que resuelva los problemas generados por la democracia representativa, sobre todo la "fatiga democrática", pero sin prescindir de aquélla, ya que su operatividad sigue siendo válida para estructurar gobiernos en países sobre todo de amplia extensión territorial y gran diversidad o pluralidad social y política, como es el caso de México. La idea no es confrontar ambas formas de gobierno: la democracia representativa versus la democracia participativa, sino encontrar la fórmula adecuada para la fusión de las dos, con una suerte de maridaje de conveniencia mutua. ${ }^{64} \mathrm{La}$ democracia representativa necesita revigorarse frente al presente desencanto ciudadano, con el vigoroso acicate de la democracia participativa o directa. Por su parte, ésta requiere también de la presencia de los representantes. La sociedad comercial actual que describió Constant en su célebre discurso no puede prescindir de ellos y regresar al modelo de la libertad de los antiguos. Para esa fusión es necesario estar conscientes de las desigualdades que inhiben la participación ciudadana con el ánimo de proponer procesos institucionales eficaces, en donde la ciudadanía se involucre en las decisiones públicas que afectan a la comunidad donde viven, pero también al conjunto nacional.

La integración de ambas categorías (democracia representativa y democracia participativa) no es ciertamente una tarea sencilla. Por el contrario, requiere de mucha ingeniería constitucional, con base en una amplia negociación política no sólo con la parte institucional (gobierno y partidos políticos), sino también con la no institucional (organizaciones sociales), pues finalmente lo que se busca es el acercamiento entre los representantes y las demandas de los ciudadanos. Por lo mismo, no se trata tan sólo de insertar las figuras de la democracia participativa en el texto constitucional, sino de acomodarlas armónicamente en el mismo con las ya existentes de la democracia representativa, lo que necesariamente supondrá diversos ajustes y alteraciones en esta última. Por ejemplo, la figura de la revocación de mandato a la mitad del periodo presidencial requiere ponderar sus consecuencias tanto para el caso de una confirmación como de su negativa desde antes de la elección, de tal suerte que el electorado tenga plena conciencia de que elige a un representante presidencial para un periodo de seis años, que puede terminar en tres, y consecuentemente, se activaría un

64 Como ha sido el caso ya mencionado anteriormente de la integración en el mismo texto constitucional de los derechos individuales, los sociales y los colectivos, lo que se logró a partir del Congreso Constituyente de 1917 entre las dos primeras categorías, y a lo largo de su ya cumplido primer centenario entre estas y la tercera. 
mecanismo para concluir el mandato. Igual análisis se requiere para todas y cada una de las modalidades de la democracia directa arriba expuestas.

Con la nueva Constitución de la CdMx, las reformas en las Constituciones locales, y las reformas constitucionales sobre nuevas figuras de democracia directa, en la carta federal, estará a prueba en la práctica, la armonización de la democracia representativa y la democracia participativa en México.

\section{BIBLIOGRAFÍA}

CAdena RoA, Jorge y LóPez Leyva, Miguel Armando, El malestar con la representación en México, México, UNAM, Instituto de Investigaciones Sociales-Centro de Investigaciones Interdisciplinarias en Ciencias y Humanidades-Ficticia Editorial, 2019.

Carbonell, Miguel et al., Neoconstitucionalismo(s), 4a. ed., México, UNAM-Trotta, 2009.

Constant, Benjamin, "Discurso sobre la libertad de los antiguos comparada con la de los modernos", pronunciado en El Ateneo de París, en Curso de Política Constitucional, tomo tercero, traducción de Marcial Antonio López, Madrid, Imprenta de la Compañía, 1820.

Cuenca Botey, Luis Emilio, “Acción, decisión y competencias deliberativas en el presupuesto participativo de Porto Alegre", Rev. Ciencias Sociales, Universidad de Costa Rica. 2008.

Madison, James (1787), The Federalist No. 10, The Utility of the Union as a Safeguard Against Domestic Faction and Insurrection (continued) (puede consultarse su versión electrónica en: http://www.constitution. org/fed/federa10.htm).

Figueroa Ávila, Enrique, Candidaturas independientes en México, déficit de la validez de la legislación 2012-2017 en materia de su registro conforme al sistema interamericano de los derechos humanos, tesis para obtener el grado de doctor en derecho por la Universidad Panamericana, México, 2019.

Gargarella, Roberto, Crisis de la representación política, México, Fontamara, 1997

KELSEN, Hans, Teoría general del Estado, traducción del alemán de Luis Legaz Lacambra, México, Editora Nacional, 1965.

Esta obra está bajo una Licencia Creative Commons Atribución-NoComercial-SinDerivar 4.0 Internacional, IIJ-UNAM. 
LEVITSKi, Steven y ZiBLATT, Daniel, Cómo mueren las democracias, México, Ariel, 2018.

LEPSIUS, Oliver, "El redescubrimiento de Weimar por parte de la doctrina del derecho político de la república federal", "Die Wiederentdeckung Weimars durch die bundesdeutsche Staatsrechtslehere", en CHISTOPH, Gusy (ed.), Weimars lange Schatten - "Weimar" als Argument nach 1945, trad. de Ignacio Gutiérrez, Gutierrez, Baden-Baden, Nomos, 2003.

LINZ, Juan, Democracy: Presidential or Parlamentary. Does it Make a Difference?, Manuscript, Yale University, 1984.

Mounk, Yascha, The People vs Democracy, Cambridge, Harvard University Press, 2018.

Pateman, Carole, Participatory Democracy Revisited, APSA Presidential Address, 2012.

Rabasa GamboA, Emilio, ¿Por qué la democracia? Transiciones de 1974 a 1990, México, UNAM, 1993.

RABASA GAMBOA, Emilio, De súbditos a ciudadanos: sentido y razón de la participación política, México, Miguel Angel Porrúa-UNAM, 1994.

RABASA GAMBOA, Emilio, "Las reformas constitucionales en materia político-electoral", Ochenta años de vida constitucional en México, México, Cámara de Diputados, 1998.

RABASA GAMBOA, Emilio, Las reformas constitucionales en materia político-electoral, edición bilingüe, México, UNAM, Instituto de Investigaciones Jurídicas-ONU, 2012.

SAlmorán, Guadalupe, Bolivia, Ecuador y Venezuela: ¿un nuevo constitucionalismo latinoamericano, o nuevas autocracias plebiscitarias?, Diritto \& Questioni Pubbliche 12 (2), 2016.

Temelkuran, Ece, Cómo perder un país, Barcelona, Anagrama, 2019.

VAN ReYBrouck, David, Contra las elecciones -cómo salvar la democracia, México, Taurus, 2017.

WALKER, Jack, "A Critique of the Elitist Theory of Democracy", The American Political Science Review, vol. 60, núm. 2 (1966).

Fecha de recepción: 24 de julio de 2019.

Fecha de aceptación: 04 de abril de 2020.

Esta obra está bajo una Licencia Creative Commons

Atribución-NoComercial-SinDerivar 4.0 Internacional, IIJ-UNAM. 